\title{
Modelling of the shape of red heartwood in beech trees (Fagus sylvatica L.) based on external tree characteristics
}

\author{
Holger WERNSDÖRFER ${ }^{\mathrm{a}, \mathrm{b} *}$, Gilles LE MOGUÉDEC ${ }^{\mathrm{a}}$, Thiéry CONSTANT ${ }^{\mathrm{a}}$, Frédéric MOTHE ${ }^{\mathrm{a}}$, \\ Gérard NEPVEU ${ }^{\mathrm{a}}$, Ute SEELING ${ }^{\mathrm{b}}$ \\ ${ }^{a}$ LERFoB (UMR INRA-ENGREF 1092), Wood Quality Research Team, INRA Nancy Research Centre, 54280 Champenoux, France \\ ${ }^{\mathrm{b}}$ University of Freiburg, Institute of Forest Utilization and Work Science, Werderring 6, 79085 Freiburg, Germany
}

(Received 01 June 2005; accepted 13 January 2006)

\begin{abstract}
The shape of red heartwood in beech was studied on 16 trees, based on the mean red heart radius at about every $2 \mathrm{~m}$ along the stem axis up to the crown base. The longitudinal red heart shape was modelled by sections of bell-shaped curves, given by an exponential function with a fourth order polynomial term. Using individual tree parameters for the red heart width, length and height, the observed red heart shapes were closely described by the model. An approach of a predictive model at the standing tree level was developed for estimating these parameters from the diameter at breast height, height of the crown base related to total tree height and height of a possible red heart initiation point. Remaining issues concerning the model structure should be analysed on a higher number of samples. An application of the model at the log level could be developed.
\end{abstract}

red heart / model / beech / Fagus sylvatica / shape

Résumé - Modélisation de la forme du cœur rouge du hêtre (Fagus sylvatica L.) à partir de caractéristiques externes de l'arbre. La forme du cœur rouge du hêtre a été décrite sur 16 arbres par des mesures du rayon moyen du cœur rouge effectuées tous les $2 \mathrm{~m}$ de hauteur environ jusqu'à la base du houppier. La forme longitudinale du cœur rouge a été modélisée par des sections de courbe en cloche données par une fonction exponentielle avec un terme polynomial d'ordre quatre. Le modèle comprenant des paramètres arbres individuels pour les largeur, longueur et hauteur du cœur rouge décrit bien les formes de cœur rouge observées. Un modèle prédictif expérimental au niveau de l'arbre sur pied est proposé pour estimer ces paramètres à partir du diamètre à $1 \mathrm{~m}$ 30, de la hauteur relative de la base du houppier et de la hauteur d'un point d'initiation potentiel du cœur rouge. Pour élaborer un modèle plus robuste, il serait nécessaire d'analyser un échantillon plus important. Une application du modèle au niveau de la grume pourrait être développée.

cœur rouge / modèle / hêtre / Fagus sylvatica / forme

\section{INTRODUCTION}

The occurrence of larger red heartwood reduces the value of beech (Fagus sylvatica L.) roundwood considerably. European Standards [4] limit the maximum red heartwood percentage to $20 \%$ and $30 \%$ for the better quality classes A and B, respectively. The red heartwood percentage is assessed at the ends of $\operatorname{logs}$ as the diameter of the circumcircle of the red heart related to the diameter of the cross-section [3]. However, it seems that the extent and total volume of red heartwood can hardly be estimated with accuracy from the ends of logs [16] or even less in standing trees. Approaches to the quantification of the intra-tree shape of red heartwood could therefore contribute to improve wood production and quality assessment in forestry, and to increase the yield of the valuable light-coloured (white) beechwood in industrial processing.

Beech is capable of forming coloured heartwood (called a "facultative heartwood species" [2]), which can be developed

\footnotetext{
* Corresponding author:

holger.wernsdoerfer@fobawi.uni-freiburg.de
}

as red heartwood (synonyms: red heart, red core), wounded heartwood, splashing heartwood or abnormal heartwood [13]. The formation of the most frequently occurring red heartwood, which was considered in the present study, is initiated when oxygen can penetrate into the stem core of older trees [20], e.g. through dead branches or forks $[5,6,8,18,20]$. Influencing factors of the probability that red heart occurs are tree age, diameter and/or diameter increase (and possibly site characteristics), i.e. older and larger trees contain more likely red heartwood and it seems that (for a given diameter) fast grown trees show less frequent and less severe red heart formation $[6-8,16]$.

The problem with estimating the extent of red heartwood is that it seems to vary considerably in stem-axial and stem-radial directions; within any one cross-section the outer red heart border does not usually coincide with the annual rings. The overall red heart shape is often that of a spindle $[9,10]$, which illustrates that for a given tree the red heart size observed on cross-sections depends on the height of the cross-section. Concerning the modelling of red heart size, in literature it was found that the red heart diameter at $7 \mathrm{~m}$ of tree height increases with the red heart diameter at breast height $(1.3 \mathrm{~m})$ [1]; 


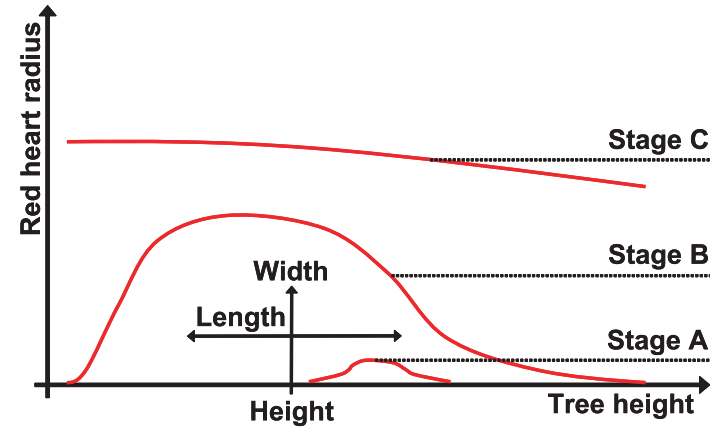

Figure 1. Rough outline of assumed stages of red heart development (referring to Zycha [20] and Wernsdörfer et al. [18]): (A) red heart initiation, (B) spindle-shaped red heart, (C) in a late stage the red heart runs almost in parallel to the bark. The red heart shape was characterised by its position (height) in the tree as well as by its stemaxial extent (length) and stem-radial extent (width).

the red heart diameter at breast height increases with the red heart diameter at stump height $(0.3 \mathrm{~m})$ [9]. At one fifth of total tree height the mean red heart radius was found to be related to the mean tree radius at this tree height and to the distance to the crown base [17]. In a multiple regression analysis based on the red heart diameter at the bottom and top ends of butt-logs, the height of the cross-section and its square were used for considering the spindle shape of red heartwood, the red heart diameter being furthermore dependent on the diameter at breast height, the mean diameter increase, the number of oxygen entrances and site characteristics [6]. Starting from several combinations of the types of red heartwood, splashing heartwood and white wood without discoloration, appearing at the bottom and top ends of butt-logs, the diameters of red and splashing heartwood dependent on the diameter at breast height were analysed by non-linear regression models [14].

To our knowledge the existing models for estimating the red heart extent were based on a rather high number of trees, but on few cross-sections per tree on which the red heart was measured. The present study proposes a closer examination of the red heart extent along the stem axis of individual trees. Its objective was to develop a modelling approach for the intra-tree shape of red heart in beech, which can take into account factors initiating and influencing red heart formation. The structure of the model should be suitable to closely describe the red heart shape, and to develop a predictive model using external tree characteristics as explanatory variables.

In the present study the assumption was made that the shape of red heartwood results from the conditions of red heart initiation and development until the point in time of observation. Referring to Zycha [20] red heart formation starts at a middle stem height and develops to the stem base and about up to the crown base. In Figure 1 three assumed stages of such a development are roughly outlined: (A) red heart initiation, (B) spindle-shaped red heart and (C) a late stage where the red heart runs almost in parallel to the bark. Stages B and C were observed on sample trees B01 and C06 of a previous study [18], respectively. Despite the course of this development can hardly be measured so far - this was the case in the

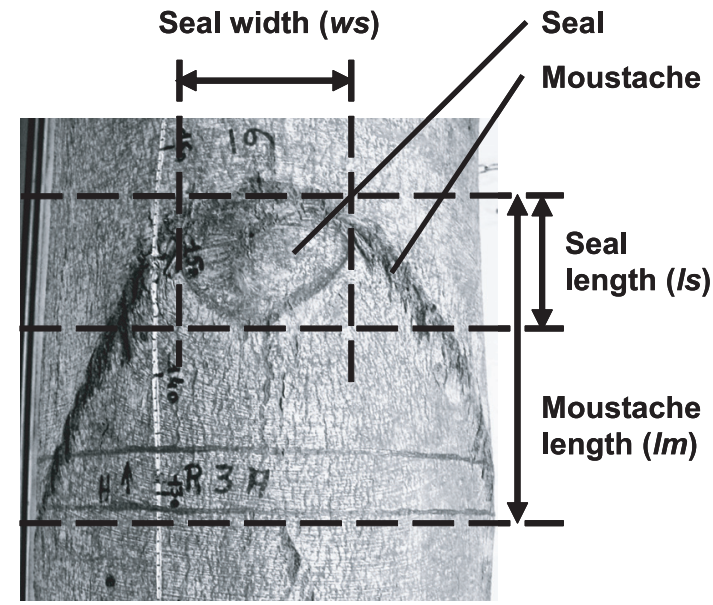

Figure 2. Branch scar consisting of the so-called seal and moustache. Measured variables seal length $(l s)$, seal width $(w s)$ and moustache length $(l m)$. Figure adopted from Wernsdörfer et al. [19].

present study, too - the red heart shape might be related to the conditions which can still be observed and measured at the point in time of the analysis. In this respect we tested the following simple hypotheses:

H1: the position (height, Fig. 1) of the red heart in the stem is related to the height(s) of its initiation point(s);

H2: the stem-axial extent (length, Fig. 1) of red heartwood is related to height characteristics of the crown (crown base, crown length);

H3: the stem-radial extent (width, Fig. 1) of red heartwood is related to secondary tree growth characteristics (diameter, diameter increase or age).

\section{MATERIAL AND METHODS}

The study was based on 16 beech trees (Fagus sylvatica L.), which were selected from a high-forest stand in the German federal state of Hesse. The minimum diameter at breast height (over bark) of the trees sampled was set to $40 \mathrm{~cm}$. Observing cross-sections of logs after felling and bucking, trees were only selected if the type of coloured heartwood was red heart according to the classification by Sachsse [13]: the splashing and abnormal heartwood types were excluded as their formations seem to differ from that of normal red heartwood, and since red heartwood occurs much more frequently. Furthermore, preferably those trees were selected which had a red heart diameter of approximately one third of the diameter of the cross-section: such trees were of interest as they were assumed to represent about a medium stage of red heart development (stage B in Fig. 1) with considerable variation of red heart shape. Discs were sampled from each tree close to the felling cut, at breast height $(1.3 \mathrm{~m})$ and above breast height at about every $2 \mathrm{~m}$ along the stem axis. The highest disc was cut just above the crown base. The crown base was defined as the lowest living primary branch, and the height of the lower ends of the moustache (Fig. 2) of this branch was measured after felling. On the inter-disc sections (logs), the seal length $(l s)$, seal width $(w s)$ and moustache length $(l m)$ of branch scars were measured (Fig. 2; branch scars were only considered if $l s \geq 5 \mathrm{~cm}$ and $w s / l s \leq 2.3[18,19])$. The height of each 
Table I. Description of the sample trees $\left(N=16 ; d b h\right.$ : diameter at breast height (over bark); age: single tree age; $m i_{\mathrm{dbh}}$ : mean increase of dbh $(d b h /$ age $) ; h_{\mathrm{cb}}$ : height of the crown base; $h_{\mathrm{cbrel}}$ : height of the crown base related to total tree height; $c l$ : crown length; $c l_{\mathrm{rel}}:$ crown length related to total tree height; $r_{\text {meanrel }}$ : mean red heart radius per disc radius (under bark) at about $0.6 \mathrm{~m}$ and $5.3 \mathrm{~m}$ of tree height).

\begin{tabular}{|c|c|c|c|c|c|c|c|c|c|}
\hline & \multirow{2}{*}{$d b h(\mathrm{~mm})$} & \multirow{2}{*}{ age (years) } & \multirow{2}{*}{$m i_{\mathrm{dbh}}(\mathrm{mm} /$ year $)$} & \multirow{2}{*}{$h_{\mathrm{cb}}(\mathrm{m})$} & \multirow{2}{*}{$h_{\text {cbrel }}(1)$} & \multirow{2}{*}{$c l(\mathrm{~m})$} & \multirow{2}{*}{$c l_{\text {rel }}(1)$} & \multicolumn{2}{|c|}{$r_{\text {meanrel }}(1)$} \\
\hline & & & & & & & & $0.6 \mathrm{~m}$ & $5.3 \mathrm{~m}$ \\
\hline Mean & 479 & 112 & 4.3 & 13.9 & 0.45 & 16.7 & 0.55 & 0.25 & 0.43 \\
\hline Std. & 39 & 5 & 0.4 & 3.4 & 0.08 & 2.1 & 0.08 & 0.14 & 0.07 \\
\hline Min. & 420 & 101 & 3.8 & 8.4 & 0.33 & 11.3 & 0.37 & 0.04 & 0.29 \\
\hline Max. & 565 & 120 & 5.3 & 19.4 & 0.63 & 19.8 & 0.67 & 0.50 & 0.57 \\
\hline
\end{tabular}

(1): No unit; std: standard deviation; min.: minimum; max.: maximum.

branch scar was recorded as the height of the disc at the upper end of the corresponding inter-disc section. For determining single tree age, stump samples were taken, corresponding to about $30 \mathrm{~cm}$ of height above ground. A description of the sample trees is given in Table I.

In the laboratory the number of annual rings was counted on the stump samples using a binocular. Furthermore, digital images were taken of the discs and the areas of disc (under bark) and red heart were measured using the image analysis software Visilog 5.3 (NOESIS, Les Ulis, France). In the case of forks (5 out of 16 trees) and for a given tree height, the discs of both stems were measured and the respective areas were added. Finally the mean radii of disc and red heart ( $N=144$ each) were calculated from the measured areas using the formula for circular areas. Also, variations of red heart extent in different stem-radial (cardinal) directions were intensively measured, but not taken into account in the present paper.

The red heart shape of each tree, i.e. the mean red heart radius $\left(r_{\text {mean }}\right)$ versus tree height $(h)$, was estimated as section of a bellshaped curve ranging from the felling cut to the crown base. At first a descriptive model (Eq. (1)) was developed including parameters to be estimated for each individual tree $i$. The descriptive model was used to evaluate if the observed red heart shape could be appropriately described by the model structure chosen. Based on the descriptive model, a general model was developed which only used parameters having the same values for all trees, as described later in this section. The descriptive model had the following equation:

$$
\frac{r_{\text {mean }}}{r_{\text {unit }}}=\mathrm{e}^{-w_{\mathrm{i}} \cdot\left(1+k_{1} \cdot z+k_{2} \cdot z^{2}+k_{3} \cdot z^{3}+k_{4} \cdot z^{4}\right)}+\varepsilon,
$$

where $z=\frac{h-h_{\mathrm{i}}}{l_{\mathrm{i}}}$.

In Equation (1), $k_{1}, k_{2}, k_{3}$ and $k_{4}$ were parameters being constant for all trees. Referring to the hypotheses and Figure 1, the parameters $h_{\mathrm{i}}$ gave the height of the red heart in each tree $i ; l_{\mathrm{i}}$ and $w_{\mathrm{i}}$ were individual tree parameters for the length and width of red heartwood, respectively; $\varepsilon$ was the residual term; $r_{\text {unit }}$ was set to $r_{\text {unit }}=1 \mathrm{~mm}$. The abbreviations of variables, and the units of variables and parameters used in Equation (1) and in the following parts of the present study are given in the Annexe section. An example for the effect of the parameters $h_{\mathrm{i}}, l_{\mathrm{i}}$ and $w_{\mathrm{i}}$ of Equation (1) is given in Figure 3. In general, an increase of $h_{\mathrm{i}}$ results in an increase of the height of the red heart in the tree; an increase of $l_{\mathrm{i}}$ results in an increase of the red heart length; and an increase of $w_{\mathrm{i}}$ results in a decrease of the red heart width (the same is true vice-versa).

Secondly, starting from Equation (1), a general model for all sampled trees was developed. In this model the individual tree parameters were estimated from explanatory variables. The development of this so-called predictive model included the following steps:

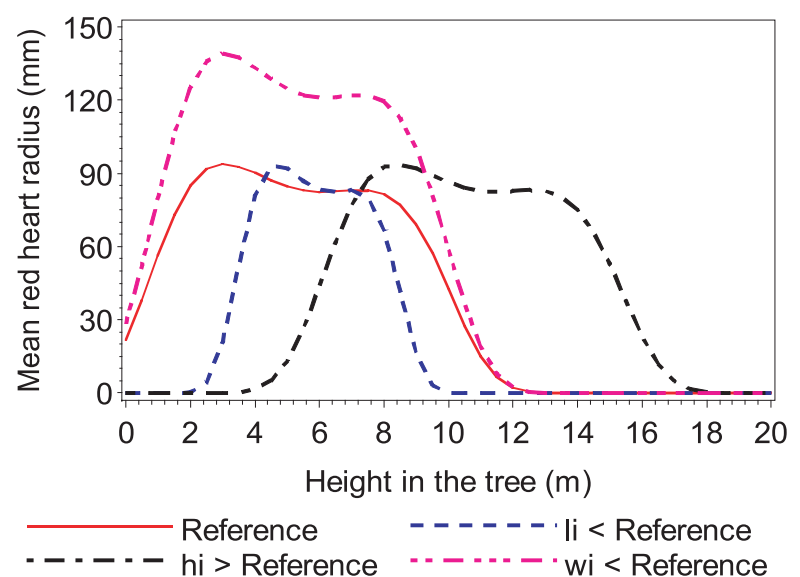

Figure 3. Example for the effect of the parameters length $\left(l_{\mathrm{i}}\right)$, height $\left(h_{\mathrm{i}}\right)$ and width $\left(w_{\mathrm{i}}\right)$ of red heartwood (Eq. (1)): by reducing $l_{\mathrm{i}}$ the reference curve (continuous line) was pushed together (broken line), by increasing $h_{\mathrm{i}}$ the reference curve was moved in direction of the abscissa (line broken by single dots), by reducing $w_{\mathrm{i}}$ the reference curve was extended in ordinal direction (line broken by several dots).

(a) Relationships between individual tree parameters: applying Equation (1) to the sample trees, estimates of $h_{\mathrm{i}}, l_{\mathrm{i}}$ and $w_{\mathrm{i}}$ were obtained for each tree $i$. From scatter plots it was assessed that $l_{\text {i }}$ was about linearly related to $h_{\mathrm{i}}$. Replacing in Equation (1) $l_{\mathrm{i}}$ by

$$
l_{\mathrm{i}}=k_{0} \cdot h_{\mathrm{i}}
$$

the model structure was simplified and the number of parameters reduced by one:

$$
\frac{r_{\text {mean }}}{r_{\text {unit }}}=\mathrm{e}^{-w_{\mathrm{i}} \cdot\left(1+k_{1}^{\prime} \cdot z^{\prime}+k_{2}^{\prime} \cdot z^{2}+k_{3}^{\prime} \cdot z^{\prime 3}+k_{4}^{\prime} \cdot z^{4}\right)}+\varepsilon,
$$

where $z^{\prime}=\frac{h}{h_{\mathrm{i}}}$.

(b) Explanatory variables: for approaching the height of the red heart in the stem (hypothesis H1) the height of one particular knot per tree was used, which was assumed to be an important initiation point of red heart formation. This knot was chosen through a rule based on the results of a previous study [18]. In that study it was suggested that particularly larger knots with a higher inclination, having a large knot occlusion area $(k a)$, and knots with a small (relative) knot depth $(k d)$, situated close to the bark, may 
be linked to the red heart. Therefore the following variables were tested:

- $h_{\text {kamax }}$ : height of the knot with the maximum occlusion area;

- $h_{\mathrm{kdmin}}$ : height of the knot with the minimum depth.

The knot occlusion area was the estimated area of the seal (Fig. 2) right after branch occlusion. Before occlusion, presumably this area was strongly related to the area of the oxygen entrance at the junction between dead branch and stem. The estimation of the knot occlusion area

$$
k a=\pi \cdot\left(\frac{l s}{2}\right)^{2} \cdot \cos (\beta)
$$

was based on geometric relationships between the dimensions of branch scars ( $l s, w s, l m$; Fig. 2), knots (inclination $\beta$, depth $k d$ ) and red heart, which were developed in the previous study [18]. The calculation method of $\beta$, used in Equation (4), and $k d$ were also adopted from that study:

$$
\begin{gathered}
k d=\frac{w s}{l s}-1 \\
\beta=\arctan \frac{l m-0.5 \cdot l s}{r k},
\end{gathered}
$$

where $r k$ was the knot radius (the radial distance between pith and knot end); $r k$ was estimated using the relation by Schulz [15]:

$$
\frac{r k}{r o} \approx \frac{l s}{w s}
$$

As radius observed ( $r o$ ) the trunk radius at the upper end of the inter-disc section was used (at the lower end if the stem forked at the upper end).

The variables $h_{\text {kamax }}$ and $h_{\mathrm{kdmin}}$ were only calculated from branch scars occurring on inter-disc sections with red heart, i.e. at least one of the discs at the ends of these inter-disc sections showed red heart. If there were small discolorations above the upper end of the essential red heart, i.e. if there was at least one disc without red heart in between both zones, branch scars occurring in the upper discoloured zone were not taken into consideration (sample trees number 4 and 47).

Concerning hypotheses $\mathrm{H} 2$ and $\mathrm{H} 3$ the following variables were tested:

- $h_{\mathrm{cb}}$ : height of the crown base;

- $h_{\mathrm{cbrel}}$ : relative height of the crown base $\left(h_{\mathrm{cb}} / h_{\mathrm{tot}}\right)$, with $h_{\mathrm{tot}}$ : total tree height;

- $c l$ : crown length $\left(h_{\mathrm{tot}}-h_{\mathrm{cb}}\right)$;

- $c l_{\text {rel }}$ : relative crown length $\left(c l / h_{\mathrm{tot}}\right)$;

- $d b h$ : diameter at breast height;

- age: single tree age;

- $m i_{\mathrm{dbh}}$ : mean increase of dbh $(\mathrm{dbh} / \mathrm{age})$.

For testing the effect of the explanatory variables, they were included into Equation (3) as follows:

$h_{\mathrm{i}}=\mathrm{f}(x)$, where $x$ was combinations of $h_{\text {kamax }}$ or $h_{\mathrm{kdmin}}$ with $h_{\mathrm{cb}}, h_{\mathrm{cbrel}}$, $c l$ or $c l_{\text {rel }}$;

$w_{\mathrm{i}}=\mathrm{f}(y)$, where $y$ was $d b h$, age or $m i_{\mathrm{dbh}}$.

The parameters of the nonlinear models were estimated using the NLIN procedure with the Marquardt computational method in the SAS 8.2 software (SAS Institute, Cary, USA).

\section{RESULTS}

The results of the descriptive model were based on Equation (1). Concerning the predictive model (Eq. (7)) the $d b h$ resulted in the best estimation of the red heart width (hypothesis H3). The height and length of red heartwood were estimated from $h_{\mathrm{kdmin}}$ and $h_{\mathrm{cbrel}}$ :

$$
\frac{r_{\text {mean }}}{r_{\text {unit }}}=\mathrm{e}^{-\left(w_{\mathrm{a}}+w_{\mathrm{b}} \cdot d b h\right) \cdot\left(1+k_{1}^{\prime} \cdot z^{\prime \prime}+k_{2}^{\prime} \cdot z^{\prime \prime 2}+k_{3}^{\prime} \cdot z^{\prime \prime 3}+k_{4}^{\prime} \cdot z^{\prime \prime 4}\right)}+\varepsilon,
$$

where

$$
z^{\prime \prime}=\frac{h}{h_{\mathrm{a}} \cdot h_{\text {cbrel }}+h_{\mathrm{b}} \cdot h_{k d \text { min }}} .
$$

Referring to hypotheses $\mathrm{H} 1$ and $\mathrm{H} 2$, the effects of $h_{\mathrm{kdmin}}$ and $h_{\text {cbrel }}$ could not be evaluated separately, since in the predictive model a linear relationship between height and length was used (Eq. (2)). The quality of the estimation was evaluated visually on plots: Figure 4 shows for each sample tree the observed (measured) mean red heart radius $\left(r_{\text {mean }}\right)$ versus tree height $(h)$, and the corresponding values of $r_{\text {mean }}$ estimated by the descriptive and predictive model.

Figure 4 illustrates that the modelling approach (Eq. (1)) was suitable to describe the red heart shape, as the observed red heart shapes were close to the shapes given by the descriptive model. In this respect the predictive model showed rather good results for sample trees number 2, 4, 15, 22, 31 and 35 . The predicted red heart width was systematically smaller than observed for trees number 24 and 50, and systematically bigger for tree number 47 . Differences between the observed and predicted red heart height and length appeared either at the bottom (trees number $21,43,50$ ) or at the top ends (trees number $29,39,41,42,45,47)$ of the red hearts analysed. Altogether, a rather good prediction was obtained in 13 out of 16 cases for the red heart width, and in 7 out of 16 cases for the height and length. Comparing in this way observed with predicted values of $r_{\text {mean }}$, similar (but in few cases worse) results were obtained if in Equation (7) $h_{\mathrm{kdmin}}$ was replaced by $h_{\text {kamax }}$. In order to evaluate if similar knots were identified by the criteria maximum occlusion area and minimum knot depth, the scatter plot of $k a$ and $k d$ is given in Figure 5. It shows that the knots with minimum depth (one knot per tree) corresponded to knots with larger occlusion areas; within these knots the smallest occlusion area amounted to about $4700 \mathrm{~mm}^{2}$.

Table II gives the parameter estimates and the approximate $95 \%$ confidence limits of the descriptive model. In most cases the parameters of width, length and height were significant (zero was not included in the confidence limits). For few parameters the confidence limits could not be computed as the level of precision was exceeded. This was related to the small number of samples.

In Tables III and IV the statistics (parameter estimates and approximate $95 \%$ confidence limits, approximate correlation matrix of the parameter estimates) of the predictive model are listed. Similarly to the descriptive model, the confidence limits and correlation of few parameters could not be computed. The parameters of the predictive model were significant; however, partly the parameters were strongly correlated. 

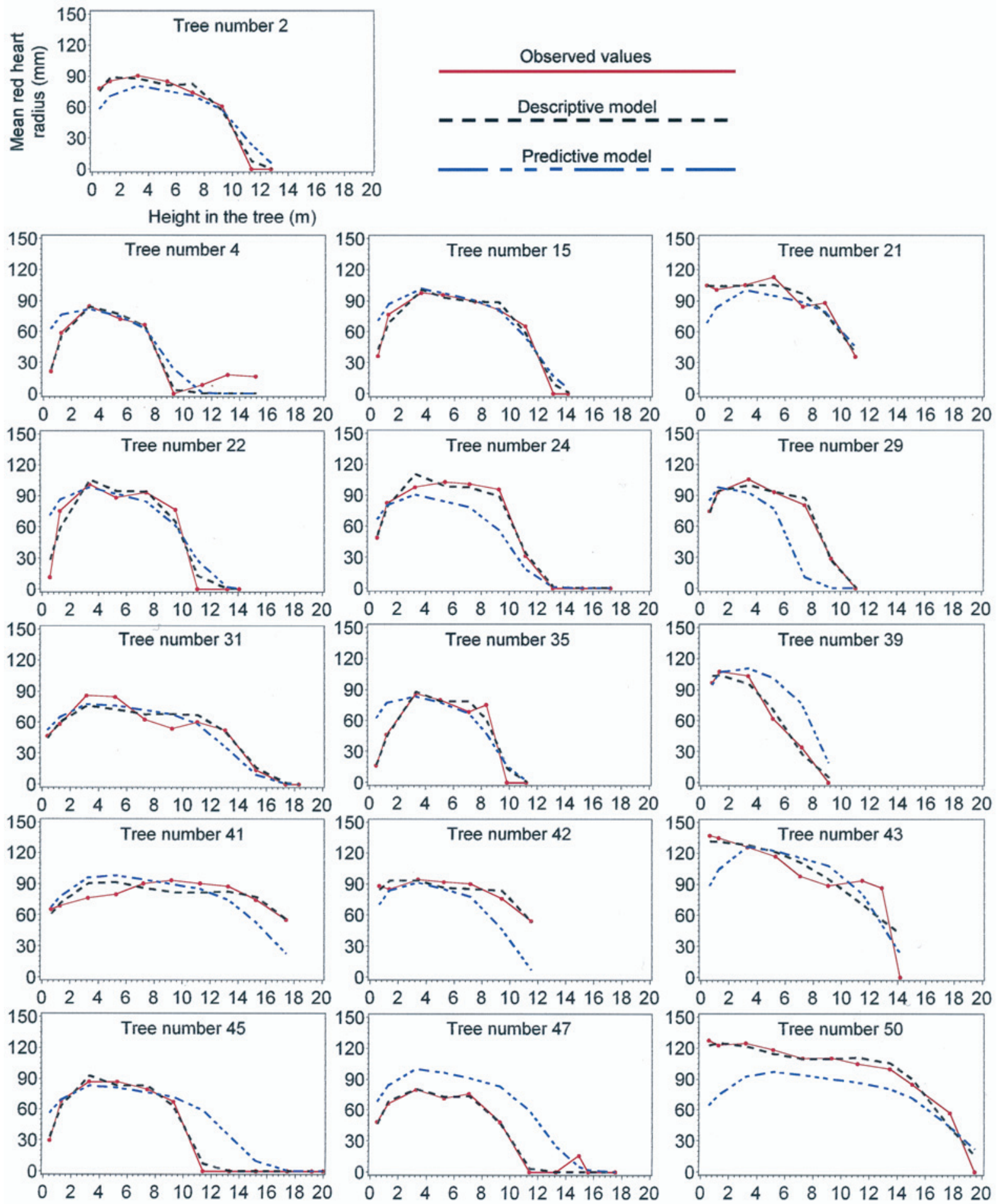

Figure 4. Mean red heart radius $\left(r_{\text {mean }}\right)$ versus tree height $(h)$ : observed (measured) values and results of the descriptive and predictive model are given for each sample tree $(N=16$ sample trees, $N=144$ mean radii). Legends of plot axes and curves are given for tree number 2 . Legends are the same for the plots of the other trees. 


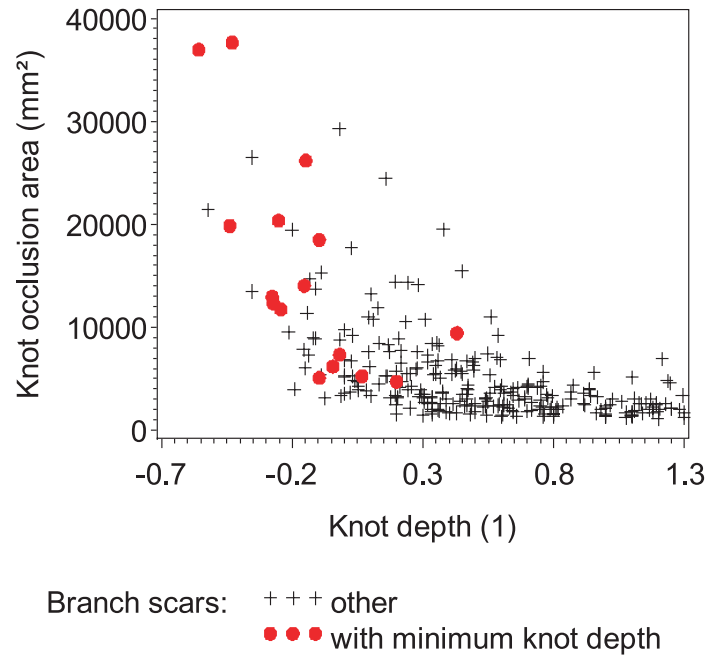

Figure 5. Scatter plot of knot occlusion area $(k a)$ and (relative) knot depth $(k d)$ of all branch scars occurring on inter-disc sections with red heart $(N=273)$. Knots with minimum depth (one per tree) are marked by dots, the others by pluses. (1) stands for no unit.

The histograms of the residuals and the scatter plots of residuals and predicted values are given in Figure 6 for the descriptive model. Figure 7 shows the corresponding results for the predictive model.

There was some structure in the residual plots for the following reasons. According to the constitution of the model, the observed values $(O V)$ should be equal to the sum of predicted values $(P V)$ and residuals $(R): O V=P V+R$. Whereas $O V \geq 0$ and $P V>0$, the residuals were supposed to be about normally distributed and could therefore be negative. Thus, if $P V$ were close to zero, it could be $P V+R<0$, but $O V \geq 0$.

\section{DISCUSSION}

With the chosen modelling approach globally promising results were obtained, but due to the constitution of the model, local problems could occur if predicted values $(P V)$ were close to zero. This might be improved by using a segmented model, which considers the cases $P V>0$ and $P V=0$, or by postulating another than the normal distribution of residuals. Furthermore, the degree of the polynomial term might be reduced to 3 or 2 in order to obtain a more robust model, since parameters $k_{1}^{\prime}, k_{2}^{\prime}$ and $k_{4}^{\prime}$ were strongly correlated. However, the parameter $k_{4}^{\prime}$ of the fourth order term was significant (Tab. III, Eq. (7)) and by keeping the third and fourth order terms (together with the first and second order terms) in the model, important characteristics of the observed red heart shape were better taken into account. Such characteristics were an extended middle section (e.g. tree number 31 at about $3.3 \mathrm{~m}$ to $11.3 \mathrm{~m}$ of tree height) or a sharp decrease of the red heart radius towards the felling cut (e.g. tree number 45 below about $3.3 \mathrm{~m}$ of tree height). Especially the latter will be of practical importance if the red heart extent is assessed at the bottom ends of logs. These issues concerning the structure of the model should be analysed, and this way the model further developed, if a larger number of samples is available.

The predictive model used the $d b h$ for estimating the width of the red heart shape. Further factors like the mean increase of $d b h$ or the possibilities of oxygen penetration [6,8] might also have an effect on this parameter. However, considering the small number of samples, only one variable was used, and the $d b h$ resulted in the best prediction of the red heart width. A similar effect of $d b h$, or stem radius at the observed tree height, on the diameter, diameter percentage or mean radius of red heartwood was found in literature $[1,6,8,17]$.

According to the predictive model of the present study, the length and height of the red heart were related to the relative height of crown base. In other studies on the one hand the mean red heart radius at one fifth of total tree height was found to be related to the distance to the crown base [17]. On the other hand factors like the mean increase of $d b h$ and the number of oxygen entrances were reported to better explain the characteristics of red heartwood (probability, diameter) than the height of the crown base [6]. Furthermore, red heart was observed to end at the zone of the crown base [10], which suggests a relationship between the red heart height and length and the crown base, also. However, the crown base is not an absolute limit of red heart extent - red heartwood can still be observed above the crown base. Thus, a closer examination of the upper red heart end might lead to a more precise estimation of the red heart height and length. In the present study these parameters were also estimated from the height of the knot with minimum depth. Probably several oxygen entrances (dead branches/branch scars, or also forks) participated in the formation of the observed red hearts, i.e. they influenced their height and length, too. Developing approaches to the quantification of the effect of single dead branches/branch scars on the occurrence of red heartwood [19] might also contribute to a better estimation of the red heart height and length (besides, in the present study the height of branch scars was recorded approximately in $2 \mathrm{~m}$ classes, which also restricts the precision of the estimation). Additionally, this estimation might then be performed completely from outside a standing tree so far branch scars occurring in stem sections with red heart were selected based on the information about red heartwood available on cross-sections. The final aim would be to link the above-mentioned model of red heart occurrence [19] to the present model of red heart shape: to estimate at first the probability that red heart occurs (does not occur) in individual trees, and to estimate at second the red heart shape of the trees which were found to contain red heart. To reach this aim and to widen the scope of model application, the models should be developed and validated using a higher number of trees from different silvicultural situations. In view of an application in forestry practice, model development should also evaluate if the effect of branch scars can be assessed by a simpler rule. Furthermore, based on the model of the present study which was developed for standing trees, a similar model may be developed to estimate red heart shape within logs after felling. Such a model could use explicitly the red heart size on crosssections of logs as an explanatory variable. This would probably lead to a more precise prediction of the red heart shape. 
Table II. Descriptive model: parameter estimates, approximate standard errors and 95\% confidence limits.

\begin{tabular}{|c|c|c|c|c|c|}
\hline \multirow[t]{2}{*}{ Tree number } & \multirow{2}{*}{$\begin{array}{c}\text { Parameter } \\
k_{1}(1)\end{array}$} & \multirow{2}{*}{$\begin{array}{l}\text { Estimation } \\
0.04600\end{array}$} & \multirow{2}{*}{$\frac{\text { Approximate standard error }}{0.00173}$} & \multicolumn{2}{|c|}{ Approximate $95 \%$ confidence limits } \\
\hline & & & & 0.0426 & 0.0494 \\
\hline \multirow{3}{*}{ all } & $k_{2}(1)$ & -0.009159 & - & - & - \\
\hline & $k_{3}(1)$ & 0.0006679 & - & - & - \\
\hline & $k_{4}(1)$ & -0.00001648 & $2.956 \cdot 10^{-7}$ & -0.00002 & -0.00002 \\
\hline 2 & $w_{2}(1)$ & -4.2067 & 0.0734 & -4.3524 & -4.0609 \\
\hline 2 & $l_{2}(\mathrm{~m})$ & 0.4521 & 0.0347 & 0.3832 & 0.5209 \\
\hline 2 & $h_{2}(\mathrm{~m})$ & 0.2195 & 0.4805 & -0.7347 & 1.1736 \\
\hline 4 & $w_{4}(1)$ & -4.1457 & 0.0893 & -4.3230 & -3.9685 \\
\hline 4 & $l_{4}(\mathrm{~m})$ & 0.3069 & 0.0232 & 0.2608 & 0.3530 \\
\hline 4 & $h_{4}(\mathrm{~m})$ & 1.4642 & 0.1724 & 1.1219 & 1.8065 \\
\hline 15 & $w_{15}(1)$ & -4.2903 & 0.0680 & -4.4253 & -4.1553 \\
\hline 15 & $l_{15}(\mathrm{~m})$ & 0.4760 & 0.0233 & 0.4298 & 0.5222 \\
\hline 15 & $h_{15}(\mathrm{~m})$ & 1.4337 & 0.2237 & 0.9896 & 1.8778 \\
\hline 21 & $w_{21}(1)$ & -4.4428 & 0.0805 & -4.6026 & -4.2830 \\
\hline 21 & $l_{21}(\mathrm{~m})$ & 0.8868 & 0.2800 & 0.3308 & 1.4428 \\
\hline 21 & $h_{21}(\mathrm{~m})$ & -8.5046 & 5.9746 & -20.3674 & 3.3582 \\
\hline 22 & $w_{22}(1)$ & -4.3319 & 0.0706 & -4.4721 & -4.1917 \\
\hline 22 & $l_{22}(\mathrm{~m})$ & 0.3910 & 0.0176 & 0.3559 & 0.4260 \\
\hline 22 & $h_{22}(\mathrm{~m})$ & 1.7049 & 0.1718 & 1.3638 & 2.0460 \\
\hline 24 & $w_{24}(1)$ & -4.3725 & 0.0671 & -4.5058 & -4.2393 \\
\hline 24 & $l_{24}(\mathrm{~m})$ & 0.4444 & 0.0205 & 0.4037 & 0.4851 \\
\hline 24 & $h_{24}(\mathrm{~m})$ & 1.2995 & 0.2022 & 0.8981 & 1.7009 \\
\hline 29 & $w_{29}(1)$ & -4.3355 & 0.0736 & -4.4818 & -4.1893 \\
\hline 29 & $l_{29}(\mathrm{~m})$ & 0.3785 & 0.0215 & 0.3358 & 0.4212 \\
\hline 29 & $h_{29}(\mathrm{~m})$ & 0.7663 & 0.2562 & 0.2575 & 1.2750 \\
\hline 31 & $w_{31}(1)$ & -4.0279 & 0.0726 & -4.1721 & -3.8837 \\
\hline 31 & $l_{31}(\mathrm{~m})$ & 0.6104 & 0.0371 & 0.5367 & 0.6842 \\
\hline 31 & $h_{31}(\mathrm{~m})$ & 1.0307 & 0.4358 & 0.1654 & 1.8960 \\
\hline 35 & $w_{35}(1)$ & -4.1650 & 0.0784 & -4.3207 & -4.0093 \\
\hline 35 & $l_{35}(\mathrm{~m})$ & 0.3415 & 0.0177 & 0.3063 & 0.3767 \\
\hline 35 & $h_{35}(\mathrm{~m})$ & 1.7441 & 0.1850 & 1.3767 & 2.1115 \\
\hline 39 & $w_{39}(1)$ & -4.4244 & 0.0859 & -4.5950 & -4.2538 \\
\hline 39 & $l_{39}(\mathrm{~m})$ & 0.7395 & 0.1969 & 0.3486 & 1.1304 \\
\hline 39 & $h_{39}(\mathrm{~m})$ & -9.6661 & 4.3027 & -18.2093 & -1.1230 \\
\hline 41 & $w_{41}(1)$ & -4.2074 & 0.0631 & -4.3326 & -4.0822 \\
\hline 41 & $l_{41}(\mathrm{~m})$ & 0.8133 & 0.0538 & 0.7064 & 0.9202 \\
\hline 41 & $h_{41}(\mathrm{~m})$ & 1.0351 & 0.5032 & 0.0359 & 2.0342 \\
\hline 42 & $w_{42}(1)$ & -4.2471 & 0.0682 & -4.3825 & -4.1117 \\
\hline 42 & $l_{42}(\mathrm{~m})$ & 0.5643 & 0.0494 & 0.4663 & 0.6624 \\
\hline 42 & $h_{42}(\mathrm{~m})$ & -0.03691 & 0.6924 & -1.4116 & 1.3378 \\
\hline 43 & $w_{43}(1)$ & -4.6520 & 0.0829 & -4.8166 & -4.4875 \\
\hline 43 & $l_{43}(\mathrm{~m})$ & 1.9261 & 0.4433 & 1.0460 & 2.8062 \\
\hline 43 & $h_{43}(\mathrm{~m})$ & -28.7360 & 9.6776 & -47.9511 & -9.5208 \\
\hline 45 & $w_{45}(1)$ & -4.2138 & 0.0750 & -4.3626 & -4.0650 \\
\hline 45 & $l_{45}(\mathrm{~m})$ & 0.4032 & 0.0231 & 0.3574 & 0.4490 \\
\hline 45 & $h_{45}(\mathrm{~m})$ & 1.4105 & 0.2085 & 0.9965 & 1.8245 \\
\hline 47 & $w_{47}(1)$ & -4.0981 & 0.0817 & -4.2603 & -3.9358 \\
\hline 47 & $l_{47}(\mathrm{~m})$ & 0.4081 & 0.0271 & 0.3543 & 0.4618 \\
\hline 47 & $h_{47}(\mathrm{~m})$ & 0.9548 & 0.2863 & 0.3863 & 1.5233 \\
\hline 50 & $w_{50}(1)$ & -4.4892 & 0.0536 & -4.5956 & -4.3828 \\
\hline 50 & $l_{50}(\mathrm{~m})$ & 0.9012 & 0.0905 & 0.7215 & 1.0809 \\
\hline 50 & $h_{50}(\mathrm{~m})$ & -2.0291 & 1.7718 & -5.5471 & 1.4888 \\
\hline
\end{tabular}

(1): No unit. 
Table III. Predictive model: parameter estimates, approximate standard errors and 95\% confidence limits.

\begin{tabular}{|c|c|c|c|c|}
\hline \multirow{3}{*}{$\begin{array}{l}\text { Parameter } \\
k_{1}^{\prime}(1)\end{array}$} & \multirow{3}{*}{$\begin{array}{c}\text { Estimation } \\
0.6366\end{array}$} & \multirow{3}{*}{$\begin{array}{c}\begin{array}{l}\text { Approximate } \\
\text { standard error }\end{array} \\
0.1532\end{array}$} & \multirow{2}{*}{\multicolumn{2}{|c|}{$\begin{array}{c}\text { Approximate } \\
95 \% \text { confidence limits }\end{array}$}} \\
\hline & & & & \\
\hline & & & 0.3336 & 0.9396 \\
\hline$k_{2}^{\prime}(1)$ & -0.9862 & 0.1380 & -1.2591 & -0.7133 \\
\hline$k_{3}^{\prime}(1)$ & 0.6230 & - & - & - \\
\hline$k_{4}^{\prime}(1)$ & -0.1451 & 0.0262 & -0.1970 & -0.0932 \\
\hline$w_{\mathrm{a}}(1)$ & -2.5946 & 0.3080 & -3.2036 & -1.9857 \\
\hline$w_{\mathrm{b}}(1 / \mathrm{mm})$ & -0.002907 & 0.000615 & -0.00412 & -0.00169 \\
\hline$h_{\mathrm{a}}(\mathrm{m})$ & 5.8694 & 1.1014 & 3.6915 & 8.0474 \\
\hline$h_{\mathrm{b}}(1)$ & 0.2702 & 0.0525 & 0.1664 & 0.3739 \\
\hline
\end{tabular}

(1): No unit.

Table IV. Predictive model: approximate correlation matrix of the parameter estimates.

\begin{tabular}{|c|c|c|c|c|c|c|c|}
\hline & $k_{1}^{\prime}$ & $k_{2}^{\prime}$ & $k_{3}^{\prime}$ & $k_{4}^{\prime}$ & $w_{\mathrm{a}}$ & $w_{\mathrm{b}}$ & $h_{\mathrm{a}}$ \\
\hline$k_{2}^{\prime}$ & -0.99 & & & & & & \\
\hline$k_{3}^{\prime}$ & - & - & & & & & \\
\hline$k_{4}^{\prime}$ & 0.94 & -0.97 & - & & & & \\
\hline$w_{\mathrm{a}}$ & 0.26 & -0.25 & - & 0.24 & & & \\
\hline$w_{\mathrm{b}}$ & 0.17 & -0.17 & - & 0.15 & -0.90 & & \\
\hline$h_{\mathrm{a}}$ & -0.63 & 0.65 & - & -0.70 & -0.08 & -0.19 & \\
\hline$h_{\mathrm{b}}$ & -0.66 & 0.70 & - & -0.75 & -0.26 & -0.02 & 0.16 \\
\hline
\end{tabular}
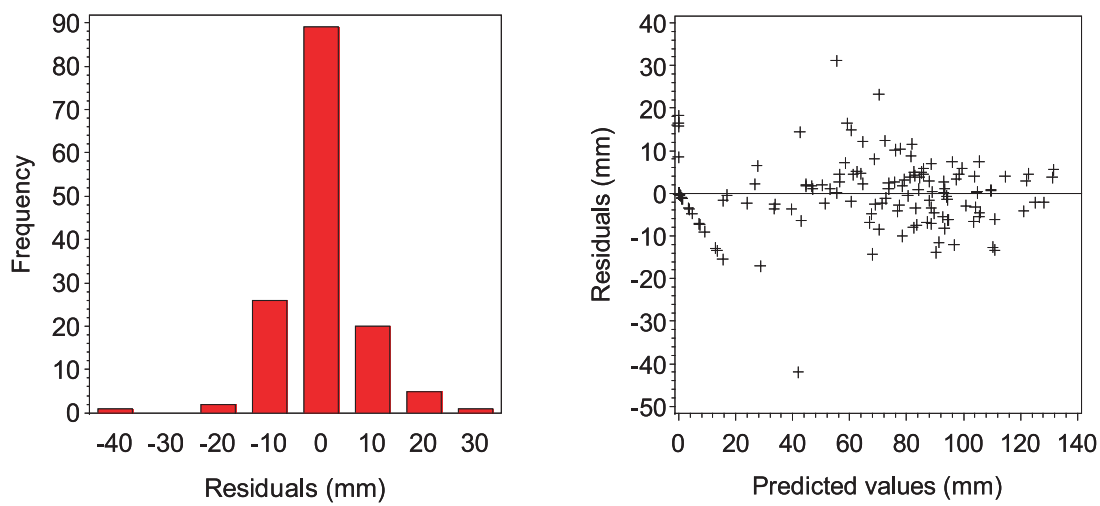

Figure 6. Descriptive model: histogram of residuals and scatter plot of residuals and predicted values $(N=144)$.
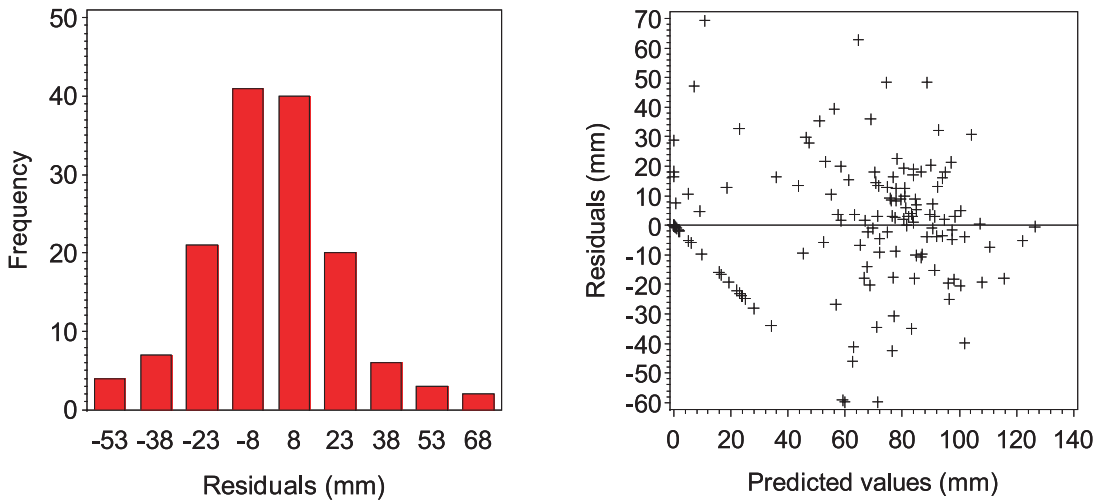

Figure 7. Predictive model: histogram of residuals and scatter plot of residuals and predicted values $(N=144)$. 
A practical application could be the estimation of red heart volume (as a body with rotation symmetry) and shape with regards to roundwood grading, for instance. Also, information about red heart shape (as presented) and other red heart characteristics (e.g. colour parameters [11] and technological properties [12]) may be useful for the development of processing methods to valorise also the red heartwood, in addition to the white beechwood.

In conclusion, an approach was presented to the modelling of the shape of red heartwood, i.e. the mean red heart radius versus tree height. The model structure was suitable to describe the observed red heart shapes, and a predictive model based on factors of red heart initiation and formation showed promising results. Concerning the constitution of the model, local problems could not be improved due to the small number of samples and should therefore be subjected to further studies. Doing so, the model might be developed to estimate red heart shape and volume in standing trees and roundwood as well. Further development of the present model should be in conjunction with a model of red heart occurrence. The corresponding analyses should include a higher number of trees from different silvicultural situations to widen the scope of model application.

Acknowledgements: The authors wish to thank H.-O. Denstorf and K.H. Spissinger (Waldgesellschaft der Riedesel Freiherren zu Eisenbach GbR, Germany) for their organisation of the field work. For carrying out field and laboratory measurements the authors are grateful to E. Cornu, C. Houssement, A. Mercanti and D. Rittié (LERFoB) as well as to E. Hummel, H. Lechner and R. Robert (University of Freiburg). This work was partly funded by a grant according to the Landesgraduiertenförderungsgesetz (LGFG) of Baden-Württemberg, Germany, and the Office National des Forêts, France.

\section{ANNEXE}

\section{Abbreviations and units of variables}

(1) Stands for no unit.

- Dendrometric: total tree height: $h_{\mathrm{tot}}(\mathrm{m})$; height of the crown base: $h_{\mathrm{cb}}(\mathrm{m})$; relative height of the crown base: $h_{\text {cbrel }}(1)$; crown length: $c l(\mathrm{~m})$; relative crown length: $c l_{\text {rel }}(1)$; diameter at breast height: $d b h(\mathrm{~mm})$; single tree age: age (years); mean increase of diameter at breast height: $m i_{\mathrm{dbh}}(\mathrm{mm} /$ year $)$.

- Branch scars: seal length: $l s(\mathrm{~mm})$; seal width: $w s(\mathrm{~mm})$; moustache length: $l m(\mathrm{~mm})$; knot occlusion area: $k a\left(\mathrm{~mm}^{2}\right)$; relative knot depth: $k d(1)$; knot inclination: $\beta(\mathrm{rad})$; knot radius: $r k(\mathrm{~mm})$ radius observed: ro $(\mathrm{mm})$; height of the knot with maximum occlusion area: $h_{\text {kamax }}(\mathrm{m})$; height of the knot with minimum depth: $h_{\text {kdmin }}(\mathrm{m})$

- Red heart: mean red heart radius: $r_{\text {mean }}(\mathrm{mm})$.

\section{Units of parameters}

- Equation (1): $k_{1}(1), k_{2}(1), k_{3}(1), k_{4}(1), h_{\mathrm{i}}(\mathrm{m}), l_{\mathrm{i}}(\mathrm{m}), w_{\mathrm{i}}(1)$;

- Equation (2): $k_{0}(1), h_{\mathrm{i}}(\mathrm{m}), l_{\mathrm{i}}(\mathrm{m})$;

- Equation (3): $k_{1}^{\prime}(1), k_{2}^{\prime}(1), k_{3}^{\prime}(1), k_{4}^{\prime}(1), h_{\mathrm{i}}(\mathrm{m}), w_{\mathrm{i}}(1)$;

- Equation (7): $k_{1}^{\prime}(1), k_{2}^{\prime}(1), k_{3}^{\prime}(1), k_{4}^{\prime}(1), h_{\mathrm{a}}(\mathrm{m}), h_{\mathrm{b}}(1), w_{\mathrm{a}}(1)$. $w_{\mathrm{b}}(1 / \mathrm{mm})$

\section{REFERENCES}

[1] Börner M., Zieldurchmesser und Rotkern bei der Buche, Forst Holz 57 (2002) 123-128

[2] Bosshard H.H., Über die fakultative Farbkernbildung, Holz Roh. Werkst. 25 (1967) 409-416.

[3] CEN, European Standard EN 1310, Round and sawn timber Method of measurement of features, European Committee for Standardization, $1997,13 \mathrm{p}$.

[4] CEN, European Standard EN 1316, Hardwood round timber, Qualitative classification, Part 1: Oak and beech, European Committee for Standardization, 1997, 6 p.

[5] Keller H., Vom Rotkern der Buche, Schweiz. Z. Forstwes. 8 (1961) 498-502.

[6] Knoke T., Eine Bewertung von Nutzungsstrategien für Buchenbestände (Fagus sylvatica L.) vor dem Hintergrund des Risikos der Farbkernbildung, Forstliche Forschungsberichte München, 2003, 200 p.

[7] Knoke T., Predicting red heartwood formation in beech trees (Fagus sylvatica L.), Ecol. Model. 169 (2003) 295-312.

[8] Knoke T., Schulz Wenderoth S., Ein Ansatz zur Beschreibung von Wahrscheinlichkeit und Ausmaß der Farbkernbildung bei Buche (Fagus sylvatica L.), Forstwiss. Centralbl. 120 (2001) 154-172.

[9] Kotar M., Gesetzmäßigkeiten der Verbreitung des Rotkerns bei der Buche, in: Kotar M., Quednau H.D. (Eds.), Deutscher Verband Forstlicher Forschungsanstalten, Sektion Forstliche Biometrie und Informatik, 7. Tagung, Biotechnical Faculty University of Ljubljana, Ljubljana, Slovenia, 1994, pp. 197-224.

[10] Krempl H., Mark E., Untersuchungen über den Kern der Rotbuche, Allg. Forstztg. (Wien) 73 (1962) 186-191.

[11] Liu S., Loup C., Gril J., Dumonceaud O., Thibaut A., Thibaut B. Studies on European beech (Fagus sylvatica L.). Part 1: Variations of wood colour parameters, Ann. For. Sci. 62 (2005) 625-632.

[12] Pöhler E., Klingner R., Künniger T., Beech (Fagus sylvatica L.) Technological properties, adhesion behaviour and colour stability with and without coatings of the red heartwood, Ann. For. Sci. 63 (2006) 129-137.

[13] Sachsse H., Kerntypen der Rotbuche, Forstarchiv 62 (1991) 238-242.

[14] Schmidt M., Vorkommen und Ausprägung von fakultativen Kerntypen bei Rotbuche auf südniedersächsischen Kalk- und Rötstandorten, in: Nagel J. (Ed.) Deutscher Verband Forstlicher Forschungsanstalten, Sektion Ertragskunde, Jahrestagung 2004, Stift Schlägl (Austria), 2004, pp. 51-68.

[15] Schulz H., Die Beurteilung der Qualitätsentwicklung junger Bäume, Forstarchiv 32 (1961) 89-99.

[16] Seeling U., Becker G., Red heart in beech (Fagus sylvatica L.). Is it related to tree architecture and silviculture? Occurrence and relevance for wood quality, in: Nepveu G. (Ed.), Fourth Workshop IUFRO WP 5.01.04, LERFoB/2004 INRA-ENGREF NancyFrance, Harrison Hot Springs, BC, Canada, 2002, pp. 210-218.

[17] Torelli N., Ökologische und waldbauliche Aspekte der fakultativen Farbkernbildung (Rotkern, "Discolored Wood") bei der Buche. Prognostizierung des Ausmasses des Rotkerns an stehenden Bäumen, Mitt. Bundesforsch. Forst- Holzwirts. 150 (1985) $182-204$.

[18] Wernsdörfer H., Constant T., Mothe F., Badia M.A., Nepveu G., Seeling U., Detailed analysis of the geometric relationship between external traits and the shape of red heartwood in beech trees (Fagus sylvatica L.), Trees 19 (2005) 482-491.

[19] Wernsdörfer H., Le Moguédec G., Constant T., Mothe F., Seeling U., Nepveu G., Approach to the estimation of red heart occurrence in Fagus sylvatica based on geometric relationships between branch scar development and knot dimensions, Scand. J. For. Res. 20 (2005) 448-455.

[20] Zycha H., Über die Kernbildung und verwandte Vorgänge im Holz der Rotbuche, Forstwiss. Centralbl. 67 (1948) 80-109. 